\title{
PENGARUH PENERAPAN GOOD CORPORATE GOVERNANCE TERHADAP KUALITAS LAPORAN KEUANGAN (STUDI PADA PERUSAHAAN ASURANSI AJB BUMIPUTERA KC LHOKSEUMAWE DAN PT TASPEN KC LHOKSEUMAWE)
}

\author{
Mursidah $^{1}$, Khairina ${ }^{2}$ \\ ${ }^{1,2}$ Prodi Akuntansi Fakultas Ekonomi dan Bisnis Universitas Malikussaleh Lhokseumawe \\ mursidah@unimal.ac.id
}

\begin{abstract}
This study aimed to determine the effect of Good Corporate Governance on the Quality of Financial Statements. The data used in this study were primary data obtained by distributing questionnaires to all respondents. The sample in this study amounted to 30 respondents who were selected using the Census sampling method. The data analysis method used was a simple Linear Regression method with the help of SPSS 17. The results of the study showed that Good Corporate Governance had an effect on the Quality of Financial statements partially. It is known that Good Corporate Governance has a significant effect on the Quality of Financial Statements. In addition, the R2 test showed that the value of $R$ Square was 0.192, which means that the magnitude influence of the independent variable on the dependent variable was $19.2 \%$ and the remaining $80.8 \%$ was influenced by other factors outside of this research models.
\end{abstract}

Keywords: Good Corporate Governance, Quality of Financial Statements.

\section{PENDAHULUAN}

Berbagai pelanggaran yang bertentangan dengan Good Corporate Governance pada perusahaan di Indonesia masih terjadi. Suatu perusahaan yang paling tinggi potensi korupsinya, penyimpangan tersebut terjadi karena pencatatan keuangannya tidak akurat dan proses penyusunan laporan tidak sesuai dengan ketentuan. Peristiwa ini menunjukkan betapa pentingnya masalah transparansi laporan keuangan, karena dengan ketidak transparanan ini memungkinkan timbulnya kecurangan seperti korupsi semakin marak. Kejadian ini berarti laporan keuangan pada perusahaan tersebut masih belum dikatakan berkualitas, maka dari itu penerapan Good Corporate Governance yang berdasarkan prinsip transparansi, akuntabilitas, kemandirian, pertanggungjawaban dan kewajaran diharapkan akan menciptakan insentif internal yang efektif bagi manajemen perusahaan agar laporan keuangan perusahaan tersebut dapat dikatakan andal atau berkualitas, sertar bernilai di pasar modal global, informasi tersebut harus jelas, konsisten dan dapat diperbandingkan juga menggunakan standar akuntansi yang diterima diseluruh dunia. (http://hukumonline: senin,16 juli 2012).

Good Corporate Governance (GCG) merupakan sistem yang mengatur dan mengendalikan perusahaan untuk menciptakan nilai tambah (value added) bagi semua stakeholder menekankan pentingnya hak pemegang saham untuk memperoleh informasi dengan benar, akurat dan tepat waktu serta kewajiban perusahaan untuk mengungkapkan (disclosure) secara akurat, tepat waktu, dan transparansi mengenai semua informasi kinerja perusahaan, kepemilikan, dan stakeholder (Utami 2009). Sehingga penerapan prinsip Good Corporate Governance diharapkan dapat meningkatkan kualitas laporan keuangan karena ketepatan waktu merupakan salah satu faktor penting dalam menyajikan suatu informasi yang relevan.

Perusahaan AJB untuk menerapkan GCG yang baik dihadapkan dengan beberapa hambatan. Dimana perusahaan asuransi AJB Bumiputera KC Lhokseumawe yang diresmikan pada tahun 1979 itu sudah dililit berbagai masalah, mulai dari penerapan tata kelola perusahaannya hingga mismanagement yang mempengaruhi neraca keuangan dimana juga akan berimbas pada kualitas laporan keuangannya. (http://bisnis.liputan6.com: Selasa,7 Februari 2017.

Seperti yang terjadi PT. TASPEN (PERSERO) tahun 2017 kasus korupsi dalam sidang perdana itu,Agoes mengambil uang milik PT Taspen yang akan didepositokan.Lima kali pengiriman, PT.TASPEN mendepositokan dananya Rp.110miliar, tetapi yang didepositokan oleh Agoes 
hanya Rp12miliar. Sisa dana yang tidak didepositokan itu disetorkan kerekening atas nama PT.TASPEN yang dibuka sendiri oleh Agoes, bekerjasama dengan Agus Saputra dan Arken. Dalam pembukaan rekening ini,mereka bertiga juga telah memalsukan tandatangan Direktur Utama PT Taspen Achmad Subianto dan Direktur Keuangan Heru Maliksjah. Pembuktian tandatangan dilakukan Laboratorium Kriminalistik Mabes Polri. Setelah dana masuk kerekening PT Taspen, uang itu langsung dipindah bukukan kerekening milik Agus Saputra dan Arken dengan buku cek yang telah disiapkan oleh Agoes. Dari bantuannya itu, Agoes Rahardjo mendapatkan Rp.2,415 miliar sebagai komisi. Sisanya dibawa oleh Agus Saputra dan Arken yang sampai saat ini masih dicari polisi. Dalam sidang yang dipimpin oleh hakim Sri Sutatiek ini, Agoes didakwa telah melanggar Pasal 49 Ayat 1 Undang-Undang Nomor 10 Tahun 1998 tentang Perubahan Undang-Undang Nomor 7 Tahun 1992 tentang Perbankan jo Pasal 55 Ayat 1 KUHP. (ARN: Indonesia Copruption Watch, "Korupsi Rp.98 miliar dana Taspen Mulai disidangkan" https://antikorupsi.org/id/news/korupsi).

Dalam pengelolaan bisnis Perusahaan PT Taspen KC Lhokseumawe mengutamakan pengelolaan yang penuh amanah, transparan, dan akuntabel bebas dari korupsi, kolusi dan nepotisme dengan menerapkan prinsip-prinsip Good Corporate Governance. Maka dalam menjalankan kegiatan bisnis sehari-hari, insan Taspen berpeluang dikenakan tuduhan tindak pidana korupsi seperti yang telah terjadi.Untuk itu dipandang perlu untuk menerapkan prinsip-prinsip Good Corporate Governance yang mengatur mengenai gratifikasi dalam perusahaan.

\section{TINJAUAN PUSTAKA}

Teori keagenan (agency theory) menjelaskan tentang hubungan kontraktual antara pihak yang mendelegasikan pengambilan keputusan tertentu (principal/pemilik/pemegang saham) dengan pihak yang menerima pendelegasian tersebut (agent/direksi/manajemen).Agency theory memfokuskan pada penentuan kontrak yang paling efisien yang mempengaruhi hubungan prinsipal dan agen (Alijoyo, 2004:6).Teori mengenai hubungan keagenan ini digunakan dalam rangka untuk memahami corporate governance lebih dalam.

Menurut Sukrisno Agoes (2011:101), istilah good corporate governance (GCG) sekarang ini sudah sangat populer, namun sampai saat ini belum ada definisi buku yang dapat disepakati oleh semua pihak. Istilah "corporate governance" pertama kali diperkenalkan oleh Cadbury Committee Inggris di tahun 1992 yang menggunakan istilah tersebut dalam laporannya yang kemudian dikenal sebagai Cadbury Report. Istilah ini sekarang menjadi sangat populer dan telah diberi banyak definisi oleh berbagai pihak.

Menurut Moh Wahyudin Zarkasy (2008:38) mengemukakan lima prinsip GCG, yaitu : Transparansi (transparency), Akuntabilitas (accountability), Responsibilitas (responsibility), Independensi (independency), Kesetaraan (fairness).

Laporan keuangan menurut Farid dan Siswanto dalam Irham Fahmi (2014:2) adalah: "Laporan keuangan merupakan informasi yang diharapkan mampumemberikan bantuan kepada pengguna untuk membuat keputusan ekonomi yang bersifat finansial". Pengertian kualitas pelaporan keuangan dapat dipandang dalam dua sudut pandang. Pandangan pertama menyatakan bahwa kualitas pelaporan keuangan berhubungan dengan kinerja keseluruhan perusahaan yang tercermin dalam laba perusahaan. Pandangan ini menyatakan bahwa laba yang berkualitas tinggi terefleksikan pada laba yang dapat berkesinambungan (sustainable) untuk suatu periode yang lama. Pelaporan keuangan dikatakan tinggi/berkualitas jika laba tahun berjalan dapat menjadi indikator yang baik untuk laba perusahaan di masa yang akan datang (Lev dan Thiagarajan, 1993; Penman dan Zhang, 1999; Richardson et al, 2001; Beneish dan Vargus, 2002; Richardson, 2003 dalam Fanani, 2009) atau berasosiasi secara kuat dengan arus kas operasi di masa yang akan dating (Dechow dan Dichev 2002; Cohen 2003 dalam Fanani 2009).

Seperti yang dilakukan oleh Ony Widi lestari ningtyas (2012) dalam penelitiannya yang berjudul "Pengaruh Penerapan Good Corporate Governance (GCG) Terhadap Kualitas Laporan Keuangan Pada PT PLN (Persero) Distribusi Jawa Barat dan Banten". Hasil penelitiannya menunjukan bahwa Secara garis besar PT PLN (Persero) Distribusi Jawa Barat dan Banten dalam penerapan good corporate governance adalah baik, karena sesuai dengan prosedur dan aturan yang telah ditetapkan oleh SK Menteri BUMN Nomor : KEP 117/117/MMBU/2002 dan memiliki kualitas laporan keuangan yang sesuai dan dapat digunakan oleh pemakai laporan keuangan dalam pengambilan keputusan.

\section{METODELOGI PENELITIAN}

\section{Objek dan Lokasi Penelitian}

Objekdalam Penelitian ini adalah Good Corporate Governance (GCG) dan Kualitas Laporan Keuangan.Sedangkan lokasi penelitian ini dilakukan 
pada Perusahaan Asuransi AJB Bumiputera KC Lhokseumawe dan PT Taspen KC Lhokseumawe.

\section{Populasi Dan Sampel}

populasi keseluruhannya diperoleh dari kuisoner yang disebarkan kepada responden untuk mengetahui pendapat para pegawai staf bagian

akuntansi, keuangan dan perbendaharaan pada Perusahaan Asuransi AJB Bumiputera Kantor Cabang Lhokseumawe dan PT Taspen Kantor Cabang Lhokseumawe yang berjumlah 30 orang. Adapun responden dalam penelitian ini dapat dilihat pada tabel 1 berikut ini:

Tabel 1

\section{Responden Penelitian}

\begin{tabular}{|c|l|l|c|}
\hline No & \multicolumn{1}{|c|}{ Perusahaan } & \multicolumn{1}{|c|}{ Alamat } & Jumlah Responden \\
\hline 1 & $\begin{array}{l}\text { AJB Bumiputera KC } \\
\text { Lhokseumawe }\end{array}$ & $\begin{array}{l}\text { Jl. Darusalam No. 4, Kp. Jawa } \\
\text { Baru, Lhokseumawe }\end{array}$ & 17 \\
\hline 2 & $\begin{array}{l}\text { PT Taspen KC } \\
\text { Lhokseumawe }\end{array}$ & $\begin{array}{l}\text { Jl. Merdeka No.32, Simpang } \\
\text { Empat, Lhokseumawe }\end{array}$ & 13 \\
\hline
\end{tabular}

\section{Metode Pengumpulan Data}

Metode dalam mengumpulkan data yang digunakan dalam penelitian ini adalah dengan menggunakan data primer. Sumber data primer berasal dari karyawan dengan menggunakan kuisioner. Kuesioner terdiri dari pernyataan yang berkaitan dengan pengukuran variable penelitian dalam hal ini adalah Good Corporate Governance dan kualitas laporan keuangan.

\section{Definisi Operasional Variabel}

Definisi operasional variable berisikan indikator-indikator dari suatu variabel, yang memungkinkan peneliti mengumpulkan data yang relevan untuk variable tersebut. Dalam penelitian ini definisi operasional variable adalah seperti pada table 2 berikut ini ::

Tabel 2

Definisi Operasional Variabel

\begin{tabular}{|c|c|c|c|c|}
\hline No & Variable & Definisi operasional variable & Indikator & Skala \\
\hline 1. & $\begin{array}{l}\text { Good } \\
\text { Corporate } \\
\text { Governance } \\
\text { (X) }\end{array}$ & $\begin{array}{lr}\text { good corporate governance } \\
\text { merupakan rangkaian proses, } \\
\text { kebiasaan, kebijakan aturan, } \\
\text { dan institusi r yang } \\
\text { mempengaruhi pengarahan, } \\
\text { pengelolaan, } \\
\text { pengendalian suatu perusahaan } \\
\text { atau korporasi.. }\end{array}$ & 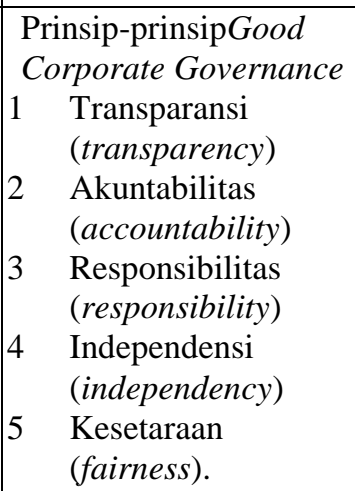 & Ordinal \\
\hline
\end{tabular}




\begin{tabular}{|c|c|c|c|c|}
\hline & & & $\begin{array}{l}\text { (Moh Wahyudin } \\
\text { arkasy, 2008:38) }\end{array}$ & \\
\hline 2. & $\begin{array}{l}\text { KualitasLap } \\
\text { oranKeuang } \\
\text { an }(Y)\end{array}$ & $\begin{array}{l}\text { kualitas pelaporan keuangan } \\
\text { berhubungan dengan kinerja } \\
\text { keseluruhan perusahaan yang } \\
\text { tercermin dalam laba } \\
\text { perusahaan.Hal ini } \\
\text { menyatakan bahwa laba yang } \\
\text { berkualitas tinggi terefleksikan } \\
\text { pada laba yang dapat } \\
\text { berkesinambungan untuk suatu } \\
\text { periode yang lama. Pelaporan } \\
\text { keuangan dikatakan } \\
\text { tinggi/berkualitas jika laba } \\
\text { tahun berjalan dapat menjadi } \\
\text { indicator yang baik untuk laba } \\
\text { perusahaan di masa yang akan } \\
\text { datang }\end{array}$ & $\begin{array}{l}\text { Karakteristik Kualitatif } \\
\text { Laporan Keaungan : } \\
\text { 1. Relevan } \\
\text { 2. Dapat Dipahami } \\
\text { 3. Kehandalan } \\
\text { 4. Dapat } \\
\quad \text { Dibandingkan } \\
\text { Sumber : Ikatan } \\
\text { Akuntan Indonesia } \\
\text { dalam SAK (2012:5) }\end{array}$ & Ordinal \\
\hline
\end{tabular}

\section{Metode Analisis}

Uji Validitas yang digunakan dalam penelitian ini adalah pengujian terhadap item pertanyaan. Pengujian terhadap validitas itemitem ini dilakukan dengan mengkorelasikan masing-masing skor butir pertanyaan dengan total skor untuk masing-masing variable menggunakan korelasi Rank Spearman. Uji Reabilitas dilakukan dengan menggunakan Split half method (spearman Brown Corellation) teknik belah dua. Kemudian dilakukan pengujian hipotesis, menentukan Koefisien Determinasi dan penarikan kesimpulan.

\section{HASIL PENELITIAN}

\section{Uji Validitas}

Uji validitas digunakan untuk mengukur sah atau valid tidaknya suatu kuisioner. Mengukur tingkat dapat dilakukan dengan cara melakukan korelasi antara skor butiran pertanyaan dengan total skor konstruk atau variabel. Adapun kriteria penilaian uji validitas adalah:

1. Apabila $r$ hitung $>r$ table, maka item kuesioner tersebut valid.

2. Apabila $r$ hitung $<r$ table, maka dapat dikatakan item kuesioner tersebut tidak valid

Tabel 3 Hasil Uji Validitas

\begin{tabular}{|l|c|c|c|c|}
\hline \multicolumn{1}{|c|}{ Variabel } & Item & Nilai $\mathrm{R}_{\text {hitung }}$ & Nilai $\mathrm{R}_{\text {tabel }}$ & Keterangan \\
\hline $\begin{array}{l}\text { Good Corporate } \\
\text { Governance (X) }\end{array}$ & 1 & 0,733 & 0.361 & Valid \\
\hline & 2 & 0,787 & 0.361 & Valid \\
\hline & 3 & 0,650 & 0.361 & Valid \\
\hline & 4 & 0,667 & 0.361 & Valid \\
\hline & 5 & 0,650 & 0.361 & Valid \\
\hline $\begin{array}{l}\text { Kualitas Laporan } \\
\text { Keuangan (Y) }\end{array}$ & 1 & 0,831 & 0.361 & Valid \\
\hline & 2 & 0,809 & 0.361 & Valid \\
\hline
\end{tabular}




\begin{tabular}{|l|l|l|l|l|}
\hline & 3 & 0,655 & 0.361 & Valid \\
\hline & 4 & 0,823 & 0.361 & Valid \\
\hline
\end{tabular}

Sumber: Hasil Penelitian (2018)

\section{Uji Reabilitas}

Suatu konstruk atau variabel dikatakan reliabelitas jika memberikan nilai Cronbach Alpha lebih besar dari 0,60. Untuk mengetahui hasil uji reliabilitas dalam penelitian ini, maka dapat dilihat pada table 4 hasil uji Reabilitas berikut di bawah ini:

Tabel 4Hasil Uji Reliabilitas

\begin{tabular}{|c|c|c|c|}
\hline Variabel & Cronbach Alpha & standat & Keterangan \\
\hline Good Corporate Governance (X) & 0,772 & 0,60 & Reliabel \\
\hline Kualitas Laporan Keuangan (Y) & 0,809 & 0,60 & Reliabel \\
\hline
\end{tabular}

Sumber: Hasil Penelitian (2018)

\section{Uji Normalitas}

Uji normalitas yang digunakan dalam penelitian ini adalah Analisis Grafik, untuk melihat normalitas residual dapat dilakukan dengan analisis grafik normal probability plot ( $\mathrm{pp}$ plot) of regression standarized residual yang membandingkan distribusi kumulatif dari distribusi normal. Berdasarkan tabel 5, maka dapat dijelaskan bahwa data yang terdistribusi sudah memenuhi kriteria normalitas pada tingkat signifikan $0,06>0,05$. Maka dapat disimpulkan bahwa data dalam penelitian ini sudah terdistribusi dengan normal.

Tabel 5 Hasil Uji Normalitas

\begin{tabular}{|ll|r|}
\hline & & $\begin{array}{c}\text { Unstandardized } \\
\text { Residual }\end{array}$ \\
\hline $\mathrm{N}$ & Mean & 30 \\
Normal Parameters & $\mathrm{a}, \mathrm{b}$ & .0000000 \\
& Std. Deviation & 2.22340712 \\
Most Extreme Differences & Absolute & .241 \\
& Positive & .149 \\
& Negative & -.241 \\
Kolmogorov-Smirnov Z & & 1.322 \\
Asymp. Sig. (2-tailed) & & .061 \\
\hline
\end{tabular}

\section{Analisis Regresi Linear Sederhana}

Persamaan regresi linear sederhana yang digunakan dalam penelitian ini adalah sebagai berikut $: \mathbf{Y}=\mathbf{a +}(\mathbf{b X})+\mathbf{e}$

Untuk mengetahui apakah model regresi benar-benar menunjukkan hubungan yang signifikan dan repsentative maka model tersebut harus memenuhi asumsi klasik regresi, untuk itu dilakukan uji normalitas, maka diperoleh hasil perhitungan analisis regresi seperti yang ditunjukkan pada Tabel 6 berikut

ini:

Tabel 6

Hasil Analisis Regresi Linear Sederhana 


\begin{tabular}{|c|c|c|c|c|c|c|}
\hline & \multirow[t]{2}{*}{ Model } & \multicolumn{2}{|c|}{$\begin{array}{l}\text { Unstandardized } \\
\text { Coefficients }\end{array}$} & \multirow{2}{*}{$\begin{array}{c}\text { Standardized } \\
\text { Coefficients } \\
\text { Beta }\end{array}$} & \multirow[t]{2}{*}{$\mathrm{t}$} & \multirow[t]{2}{*}{ Sig. } \\
\hline & & B & Std. Error & & & \\
\hline 1 & (Constant) & 5.648 & 4.238 & & 1.333 & .193 \\
\hline & $\begin{array}{l}\text { Good Corporate } \\
\text { Governance }\end{array}$ & .505 & .196 & .438 & 2.581 & .015 \\
\hline & $\begin{array}{l}\text { Koefisien } \\
\text { Determinasi }\end{array}$ & .192 & \multirow{2}{*}{\multicolumn{4}{|c|}{$\begin{array}{ll}\text { a. } & \text { Predictor : (constanta): Good Corporate } \\
\text { Governance } \\
\text { b. Dependen variabel : Kualitas Laporan } \\
\text { Keuangan }\end{array}$}} \\
\hline & Adjusted R Square & .162 & & & & \\
\hline
\end{tabular}

Sumber :Hasil Penelitian, data diolah (2018)

\section{Pengaruh GCG Terhadap Kualitas Laporan Keuangan}

Hasil pengujian variabel Good Corporate Governance (X) terhadap Kualitas laporan Keuangan (Y) diperoleh nilai $\mathrm{t}_{\text {hitung }}$ dengan nilai sebesar $2,581 \geq$ 1,706 lebih besar dari nilai $t_{\text {tabel }}$ pada tingkat kepercayaan $95 \%(\alpha=5 \%)$ sebesar signifikan $0,015 \leq 0,05$ dengan $\mathrm{df}=\mathrm{n}-\mathrm{k}=30-4=26$ diperoleh nilai $t_{\text {tabel }}$ sebesar 1,706. Maka dapat disimpulkan bahwa variabel Good Corporate Governance berpengaruh positif dan signifikan terhadap Kualitas Laporan Keuangan.dengan ini dapat disimpulkan bahwa hipotesis H0 diterima. Hasil ini menunjukkan bahwa responden menyadari bahwa dengan penerapan good corporate governance yang baik dimana perusahaan dapat mempertanggungjawabkan laporan keuangan secara transparan, akuntabilitas, resposibilitas, independensi dan wajar maka akan meningkatkan kualitas laporan keuangan perusahaan. Penelitian ini didukung oleh penelitian sebelumnya yang dilakukan oleh Yasmeenet al., (2015), Utami dan ningtyas (2007), Novatiani dan Fatimmah (2012) dimana dalam penelitiannya Good Corporate Governance berpengaruh positif dan signifikan terhadap Kualitas laporan Keuangan.

\section{KESIMPULAN DAN SARAN}

\section{Kesimpulan}

Bedasarkan hasil penelitian dan pembahasan yang telah diuraikan di bab sebelumnya. Maka dapat diambil kesimpulan:

1. Good Corporate Governance berpengaruh secara positif dan signifikan terhadap Kualitas laporan Keuangan (Studi pada Perusahaan AJB Bumiputera dan PT TASPEN KC Lhokseumawe) dilihat dari nilai $t_{\text {hitung }}$ sebesar 2.581 lebih besar dari $t_{\text {tabel }}$ sebesar 1.706, yang berarti H0 ditolak dan Ha diterima.

\section{Saran}

Bagi Perusahaan disarankan untuk meningkatkan Good Corporate Governance dengan cara memegang teguh Prisip-prinsip dari Good Corporate Governanceagar perusahaan dapat lebih meningkatkan kembali kinerja perusahaan. Bagi Peneliti Selanjutnya agar dapat mengembangkan penelitian ini dengan menggunakan metode lain atau dapat dilakukan pada populasi atau dan sector yang berbeda seperti BUMN atau BUMS dalam meneliti Good Corporate Governance misalnya melalui wawancara mendalam terhadap responden, sehingga informasi yang diperoleh dapat lebih bervariasi daripada kuesioner. Apakah ada perbedaan dengan hasil penelitian penulis, mudah-mudahan didapatkan hasil yang lebih baik lagi.

\section{DAFTAR PUSTAKA}

Agoes, Sukrisno. 2011.Auditing (Pemeriksaan Akuntan), Oleh Kantor Akuntan PublikJilid II. Jakarta : Lembaga Penerbit Fakultas Ekonomi Universitas Indonesia. 
Alijoyo, Antonius., Zaini Subarto., dan Tjager, I Nyoman. 2004. Komisari sIndependen, Jakarta: PT Indeks Kelompok Gramedia

Arikunto, Suharsimi. 2012. Prosedur Penelitian Suatu Pendekatan Praktik. Jakarta: Rineka Cipta.

Bastian, Indra. 2006. Sistem Akuntansi Sektor Publik, Edisi 2, Jakarta :Salemba Empat.

Fahmi, Irham. 2014. Analisis Laporan Keuangan, Bandung: Alfa Beta.

Fanani, Zainal. 2009. Kualitas Pelaporan Keuangan: Berbagai Faktor Penentu dan Konsekuensi Ekonomis. Jurnal Akuntansi dan Keuangan Indonesia. Volume 6 (1); 20-45.

Fraser M.Lyn dan Ormiston Alien.2004. Memahami Laporan Keuangan. Dialih bahasakan oleh Sam Setya utama.Jakarta :Indeks. edisi. Keenam

Ghozali, Imam. (2005). Aplikasi Analisis Multivariate Dengan Program SPSS

.(2011). Aplikasi Analisis Multivariate Dengan Program Ibm Spss19. Badan Penerbit Universitas Diponegoro, Semarang

Gudono.2012. Toeri Organisasi edisi 2.Yogyakarta: BPFE Fakultas Ekonomika dan Bisnis UGM.

Hayyuning Tyas Rosdiani (2011), Pengaruh Sistem Pengendalian Internal, Audit Laporan Keuangan dan Penerapan Good Corporate Governance Terhadap Kualitas Laporan Keuangan. Universitas PasundanBandung : Skripsi

Hidayat, Widi dan Elisabet. 2010. Faktor factor yang Mempengaruhi Kualitas Pelaporan Keuangan pada Perusahaan Manufaktur yang Go Public di Indonesia. Jurnal Ekonomi. Volume 1 (1).
IkatanAkuntansi Indonesia 2012,

Pernyataan Standar Akuntansi Keuangan. (PSAK) No. 5.

IAI. 2010. Standart Akuntansi Keuangan. Jakarta. Salemba Empat

Jama'an. 2008. "Pengaruh Mekanisme Corporate Governance, dan Kualitas Kantor Akuntan Publik Terhadap Integritas Informasi Laporan Keuangan: Studi Kasus Perusahaan Publik yang Listing di BEJ".Tesis tidak diterbitkan, Universitas Diponegoro, Semarang.

Keputusan Menteri BUMN Nomor 117. 2002.Penerapan Praktek Good Corporate Governance pada BUMN. Indonesia.

Nurwulandari, Dewi dan Putri Dian Saripujiana.2015.Faktor-faktor yang mempengaruhi kualitas pelaporan keuangan: studi kasus indeks lq45 yang terdaftar di bursa efek Indonesia .Jurnal Ekonomi Akuntansi.

Peraturan Pemerintah Nomor 7 tahun 2010 Tentang Standart Akuntansi Pemerintahan.

Purwanti, Titik. 2010. Analisis Pengaruh Volatilitas Arus Kas, Besaran Akrual, Volatilitas Penjualan, Leverage, Siklus Operasi, Ukuran Perusahaan, Umur Perusahaan, dan likuiditas Terhadap Kualitas Laba. Tesis. Surakarta: Program Studi Magister Akuntansi Universitas Sebelas Maret.

Novatiani, R. Ait. 2012. Pengaruh Penerapan Good Corporate Governance Terhadap Keandalan Laporan Keuangan.

Sutedi, Adrian. 2011. Good Corporate Governance, Jakarta: SinarGrafika.

Tjgger, et al. 2003.Corporate Governance: Tantangan dan Kesempatan bagi 
Komunitas Bisnis Indonesia. Jakarta. PT. Prenhal lindo

Wardhani, Ratna. 2006. Mekanisme Corporate Governance dalam Perusahaan yang mengalami Permasalahan Keuangan. Financially Distressed firms.Simposium Nasional Akuntansi IX. Padang

Widilestariningtyas, O., dan Yesi D. U., 2007, Pengaruh Penerapan Good Corporate Governance (GCG) Terhadap Kualitas Laporan Keuangan Pada PT PLN (Persero) Distribusi Jawa Barat dan Banten,Jurnal Akuntansi.

Yasmeen, Diptariana dan Sri Hermawati.2015.Pengaruh Good Corporate Governance terhadap Kualitas Laporan Keuangan pada Perusahaan Manufaktur.Jurnal Ekonomi Bisnis.Volume 20 No.1.

Utami,Yesi Denti. 2009. Pengaruh Sistem Pengendalian Intern dan GoodCorporate Governance terhadap Kualitas Laporan Keuangan. Bandung

YPPMI Institut dan FCGI. 2002. Good Corporate Governance dalam Konsep dan Implementasi Perusahaan Publik dan Korporasi Indonesia.YPPMI Sinergy Comunication.

Zarkasyi, Moh. Wahyudin. 2008. Good Corporate Governance, Bandung: Alfa Beta.

http://www.hukumonline.com/berita/baca/It 5003e488e2307/fitra--telkomberpotensi-jadi-bumn-terkorup (diakses pada senin, 16 juli 2012)

http://bisnis.liputan6.com/read/2849322/inifaktor-bikin-ajb-bumiputera-kenamasalah (diakses pada selasa, 7 februari 2017)

http://www.taspen.co.id/?page_id=45

https://antikorupsi.org/id/news/korupsi-rp98-miliar-dana-taspen-mulaidisidangkan. Diunduh pada tanggal $20 \quad$ Oktober 2018 